\title{
Determination of Load Performance of Two-Bar Girder Lining
}

\author{
Yuri Glazkov ${ }^{1}$, Anton Kazantsev ${ }^{2,3 *}$, Dmitriy Nesteruk ${ }^{3}$, Vladimir Aksenov ${ }^{2,3}$, and Andrey \\ Efremenkov ${ }^{2,3}$ \\ ${ }^{1}$ T.F. Gorbachev Kuzbass State Technical University, 28, Vesennyaya st., Kemerovo 650000, RF \\ ${ }^{2}$ Federal Research Center of Coal and Coal Chemistry of the Siberian Branch of the RAS, \\ Leningradskiy Ave10, 650065 Kemerovo, RF \\ ${ }^{3}$ Yurga Institute of Technology, TPU Affiliate, 26, Leningradskaya st., Yurga 652050, RF
}

\begin{abstract}
The article proposes a base-line design of the system in the form of lattice girders to support peripheral rock masses of workings. The design scheme and its parameters of support and loading conditions are given, the simulation results are shown. Designing a 'reinforcing' support system suitable to be installed into the channel slots formed in the surrounding rock mass and developing a process to construct this support are the prime considerations in tunnels driven using the new mining technology. Helix and longitudinal channel slots excavated by the geokhod in the border zone during tunnel excavation should be used to provide a potential for increasing bearing capacities.
\end{abstract}

\section{Introduction}

In our previous works [1-9] we mentioned that our research group has been working on the development of a new class of tunnel boring machines (TBM) called 'geokhod'. During the excavating operations, a geokhod forms a system of channel slots in the surrounding rock mass. Studying the system of excavations creates preconditions for a new approach to the ground support in underground workings and a new design of support systems. This new approach defines a framework for the research: interactions of supports in underground workings and peripheral rock masses as one of the key elements to create a new mining technology. After analyzing the works of foreign scientists [10-21] it is obvious that in recent years different types of lattice girders have been widely used in reinforced shotcrete lining to provide support in shielded TBM driving. Accounting for the available data a design of helix support with girder elements has been designed. The basic idea for creating this support is that it consists of standard bar arch segments to form the tunnel contour perimeter of a full circle (Figure 1). The study subject is a quarter circle segment, and in this case one turn of the lining consists of four identical bar girder elements.

In the process of driving, the lining is made in the way of sequential installation of new sections. The long channel slots are employed for installing longitudinal connecting elements. The purpose of this paper is describing the finite-element model of a typical

\footnotetext{
* Corresponding author: kazantsev@tpu.ru
} 
lining segment and the received results after analyzing its particular behavior under the influence of a vertical load distributed uniformly (Figure 2).

Modeling was carried using the software package ANSYS Mechanical v14.5.

The BEAM188 finite element with a quadratic function form and two nodes was used. The outer and inner bars (see Figure 1) are divided into segments to indicate the distance between adjacent nodes. A girder bar within one segment or stiffener was modeled by one finite element. The specified mesh refinement was tested by comparing the computational results of the continuous planar annulus regarding the design load as shown in Figure 2 with the results of the analytical solution to the same problem as described in [22]. The comparison showed that with 40 finite elements the discrepancy in the results as to finite element and analytical solutions does not exceed $3 \div 5$ percent. In further investigations, each bar has been modeled using minimum 40 finite elements. Figure 3 shows an example of the mesh with similar parameters.

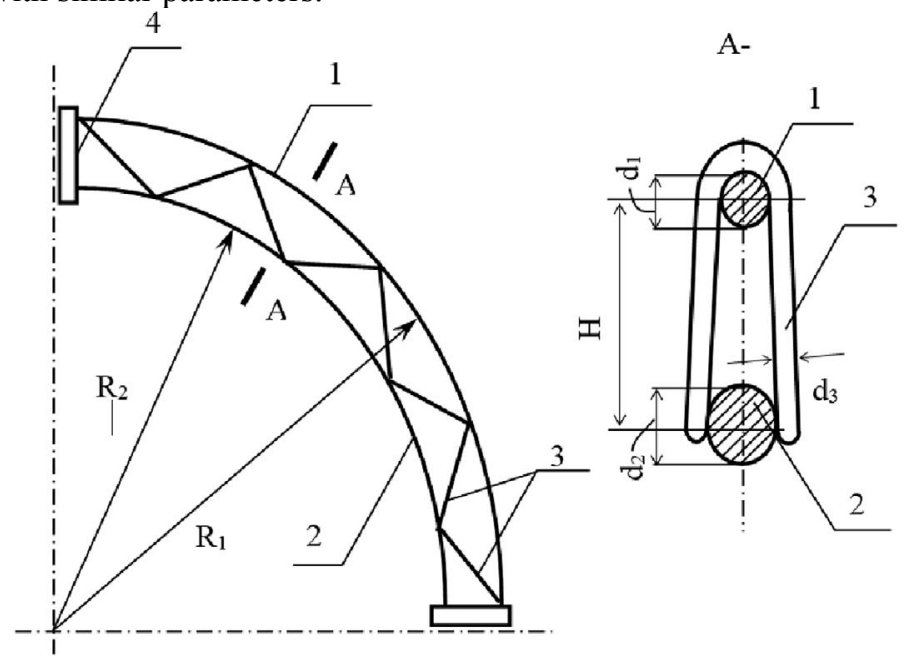

Fig. 1. Schematic design of the lining: 1 -outer bar; 2 -inner bar; 3 - stiffener; 4 -connector

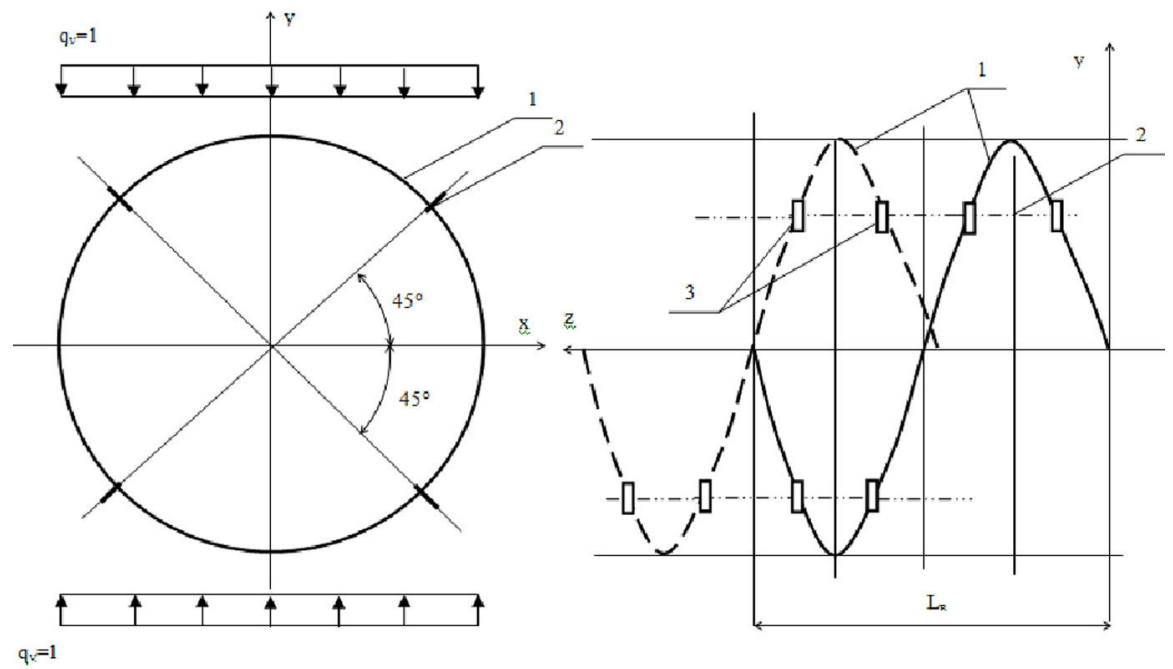

Fig. 2. Design model of the fragmented lining: 1 - support section; 2- longitudinal connecting elements; 3 - nodes of connections of the lining and connecting elements 
With the purpose of simplifying the modeling of finite element mesh the nodal connections (p.3 in Figure 2) were not analyzed in detail and taken into account only for setting kinematic links.

Links, limiting displacements, were imposed on the basis of symmetry properties. The design model of lining fragments containing any number of turns has three properties of symmetry.

First, the problem is symmetric in respect to the global coordinate plane $\mathrm{x} 0 \mathrm{z}$. When mesh nodes are uniplanar, motion along the $y$-axis direction is not possible $(U Y=0)$.

Second, where $\mathrm{UX}=0$, the symmetry in respect to the plane $\mathrm{y} 0 \mathrm{z}$ is similar.

Third, allowing for any lining fragment with a whole number of turns with the start and finish of this fragment lying in the plane of symmetry, oblique symmetry will be performed with the assumptions that the lining is infinite at its fragment ends. For example, for the mesh in Figure 3 rotations about the $y$ and $\mathrm{z}$ axes $(\mathrm{ROTY}=\mathrm{ROTZ}=0)$ are inhibited at the nodes of end sections in addition to the previously indicated links.

It should be pointed out that it is usually difficult to set correct kinematic boundary conditions for the computation of real-life structures. Regarding this problem, the similar behavior of kinematic boundary conditions with respect to all turns of the lining ensures the correctness of these boundary settings. Below it can be seen all turns behave the same way, both end and middle turns. This fact proves the specified kinematic boundary conditions are accurate.

a)

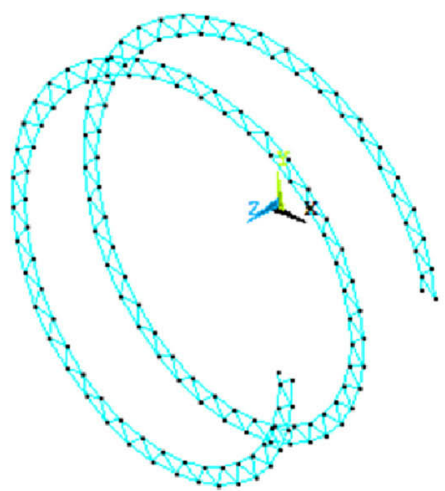

b)

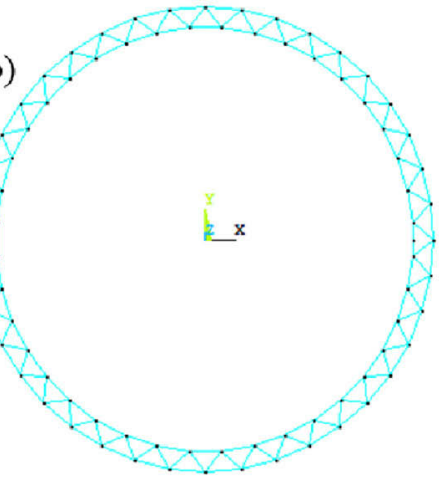

Fig. 3. Schemes of the finite element meshes for the two-turn lining fragment in axonometric (a) and front (b) projections

To unify the multiple computations of lining supports in the context of various parameters, the program-macro FOne.mac has been created using ANSYS Parametric Design Language (APDL). This program has functional capabilities to perform computations and post-process analyses of linings in terms of the design model discussed above.

Below are the results of calculation of a lining variant with parameters given in Table 1 to illustrate the program's capabilities.

When calculating we assumed that a girder element completely fits the helix channel slot and internal fiber of its cross-section had a curvature radius equal to Rк. In this case, the radii were defined as $\mathrm{R} 2=\mathrm{R \kappa}+\mathrm{d} 2 / 2=1606 \mathrm{~mm}$ for the outer bar and $\mathrm{R} 1=\mathrm{R \kappa}+\mathrm{d} 2 / 2$ $+\mathrm{H}=1757 \mathrm{~mm}$ for the inner bar. Two girder bars with a cross-section diameter $\mathrm{d} 3$ of 12 $\mathrm{mm}$ were replaced with a round bar having a diameter $\mathrm{d} 3$,эКв of $15 \mathrm{~mm}$ what is equivalent to the area of both crossbars.

The rated distributed load was programmatically replaced by its statically equivalent concentrated forces applied to the nodal connections of the outer bar of the lining cross- 
section. The connecting elements in power scheme calculating were neglected and used as safety factors.

Table 1. Values for a lining fragment

\begin{tabular}{|c|l|c|c|c|}
\hline № & \multicolumn{1}{|c|}{ Parameter } & Designation & Unit & Value \\
\hline 1 & Radius of working cross-section & $\mathrm{RK}$ & {$[\mathrm{mm}]$} & 1600 \\
\hline 2 & Diameter of outer bar cross-section & $\mathrm{d} 1$ & {$[\mathrm{~mm}]$} & 30 \\
\hline 3 & Diameter of inner bar cross-section & $\mathrm{d} 2$ & {$[\mathrm{~mm}]$} & 36 \\
\hline 4 & Stiffener Diameter & $\mathrm{d} 3$ & {$[\mathrm{~mm}]$} & 12 \\
\hline 5 & Height of lining cross-section over the axes of bars & $\mathrm{H}$ & {$[\mathrm{mm}]$} & 151 \\
\hline 6 & Length of a turn over the z-axis & LB & {$[\mathrm{mm}]$} & 800 \\
\hline 7 & Number of segments on a turn & & {$[\mathrm{pc}]$} & 40 \\
\hline 8 & Number of turns in the design model & & {$[\mathrm{pc}]$} & 2 \\
\hline
\end{tabular}

In the macro, two options for setting kinematic links in the direction of the global z-axis (longitudinal axis of the working) have been implemented. The first option implies the superposed links on all nodes of lining. This option allows for the potential for fixing the lining in the helix channel slots that results in impossible displacements along the z-axis.

The second option implies the fixing of nodes arranged in sections where the lining and longitudinal connecting elements are connected. This option has been described above. Further in this paper these options of connections will be referred to as the first and second.

Macros make possible to analyze the results of computation in the form of diagrams of internal forces or associated stresses. Thus, each bar generally meets complex resistances to bending with compression and torsion. Within this work only normal stresses applied to cross-sections of the inner and outer bars and stiffeners were discussed. They are defined according to the standard formulas of structural mechanics.

$$
\sigma^{N}=\frac{N}{A} ; \sigma^{M_{y}}=\frac{M_{y}}{W_{y}} ; \sigma^{M_{z}}=\frac{M_{z}}{W_{z}},
$$

where $\sigma^{\mathrm{N}}$ is the normal stress caused by the axial force; $\sigma^{\mathrm{My}}$ and $\sigma^{\mathrm{Mz}}$ are the maximum normal stresses caused by bending moments; $\mathrm{W}_{\mathrm{y}}$ and $\mathrm{W}_{\mathrm{z}}$ are the resisting moments of the cross-section caused by bending. When the cross-section is round, we have

$$
W_{y}=W_{z}=\frac{\pi d^{3}}{32} \approx 0,1 d^{3}
$$

It needs to note that within this investigation internal stresses and strains are related to the local axes of the finite element. The longitudinal x-axis of BEAM188 element is directed along the nodes at the ends of element. The transverse axis of the element is parallel to the global coordinate plane $\mathrm{x} 0 \mathrm{y}$. In this case, the bending moment My complies with the bending out of cross-section plane, i.e. perpendicular to the plane of acting load. In the cross-section plane (in the plane of acting load) the bending relates to the moment Mz. When analyzing the results of the computation it is necessary to consider that the tensile and compressive stresses are caused by bending at the end points of section. The stress diagram shows stresses with regard to one fiber (section side) that can be positive (tensile) or negative (compressive). Therefore, the calculated total stresses should be determined as the sum of modular values of axial forces and bending moments.

Figure 4 shows the diagrams of all stress components (1) separately for the outer bar. With this, the distribution of stresses due to axial forces $\sigma^{\mathrm{N}}$ and bending in the plane of load, when the links are superposed, are almost identical. Therefore, these stresses diagrams for the second option are shown here. The main difference in behavior at different variants 
manifests in the distribution of stresses due to bending out of the plane of load. Figure 5 shows the diagrams where the significant increase in stress components occurs locally in the vicinity of points of the longitudinal connecting elements.

\section{Conclusions}

The following conclusions emerge from this fact. The behavior of a bar in the helix girder lining significantly differs from that of in-plane lining. In the case of helix girders, there is a tendency for bars to twist relative to each other. Apparently, this fact leads to the appearance of stiffener bending out of the plane of load.

Under the conditions where stiffeners are more flexible then bars, the stresses arisen in the stiffeners are much higher than those in the bars. The stiffeners become dangerous. The influence of twist on bars can be reduced by unfixing of lining in the helix channel slots. This fact is confirmed by comparing the diagrams $\sigma^{\mathrm{My}}$ for the first and second options of securing nodes. The first option of connections reduces $\sigma^{\mathrm{Mz}}$ more than three times as compared with the second option.

The use of spatial girder constructions like 3-bar girders is another way to reduce the effect of the twisting belts.

The bearing capacity of the lining is estimated in respect to the total design stresses in critical sections of girder bars and stiffeners. The results of the design stresses are given in Table 2 .

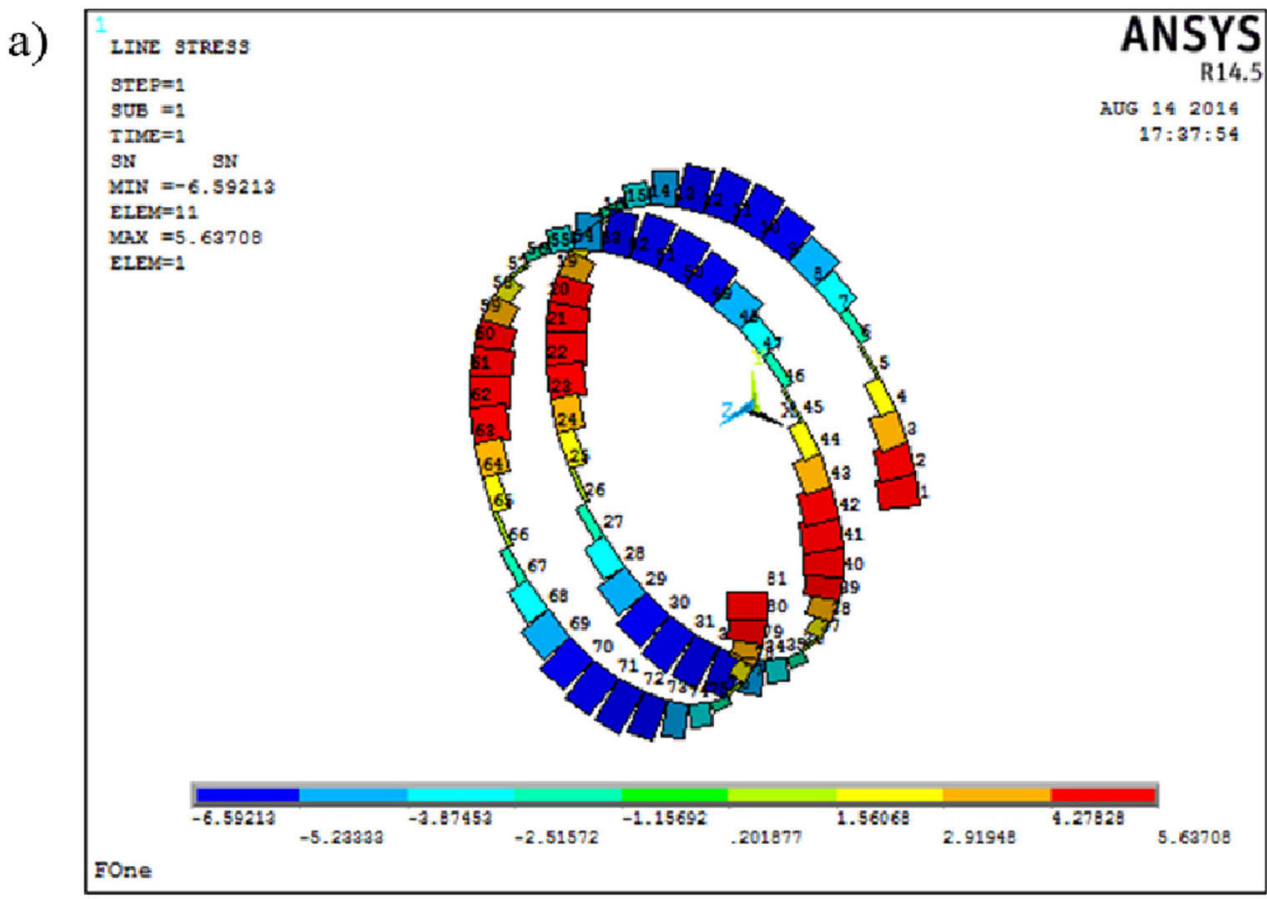


b)

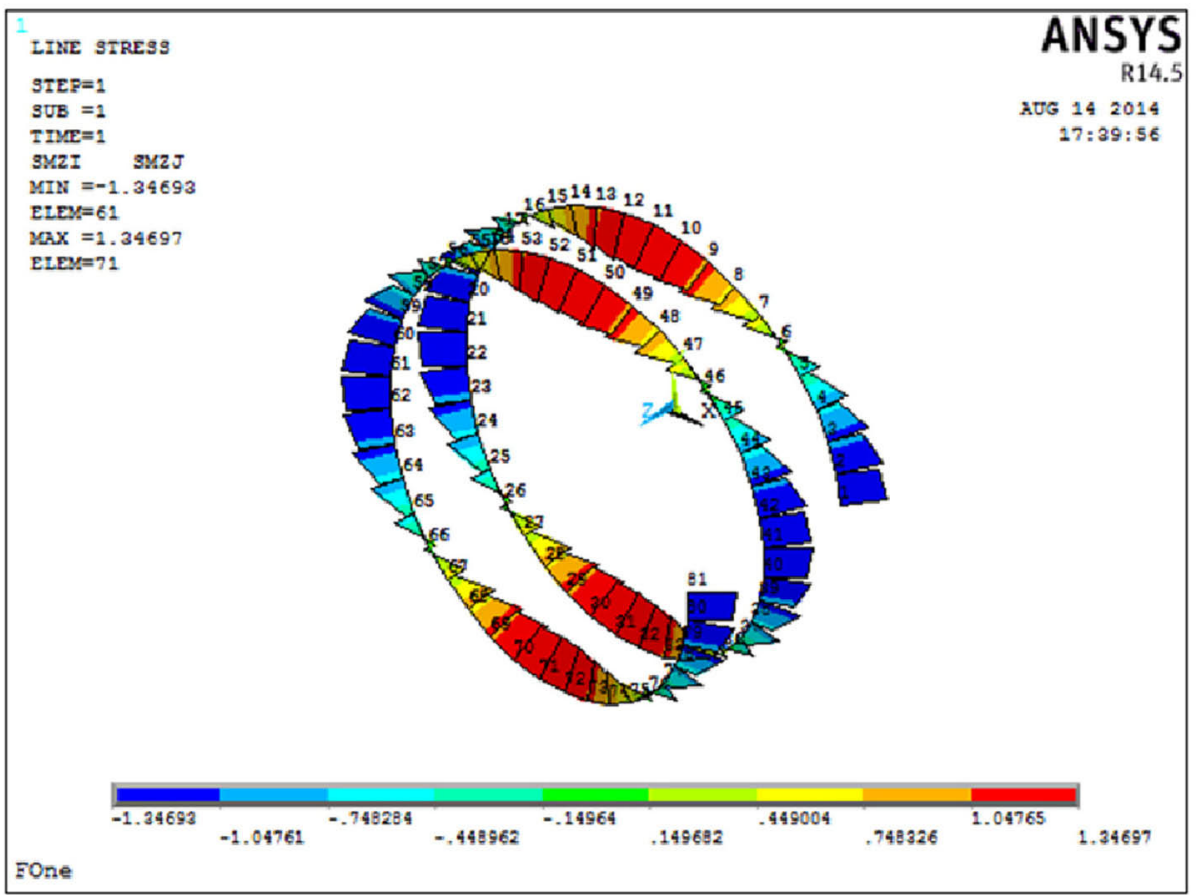

c)
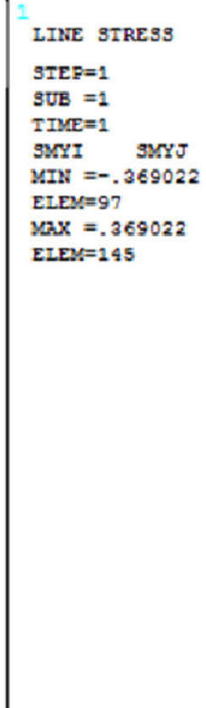

Fig. 4. Stress diagrams for outer bars $\sigma^{\mathrm{N}}$ (a); $\sigma^{\mathrm{M}_{\mathrm{z}}}$ (b) and $\sigma^{\mathrm{M}_{\mathrm{y}}}$ (c) 
a)

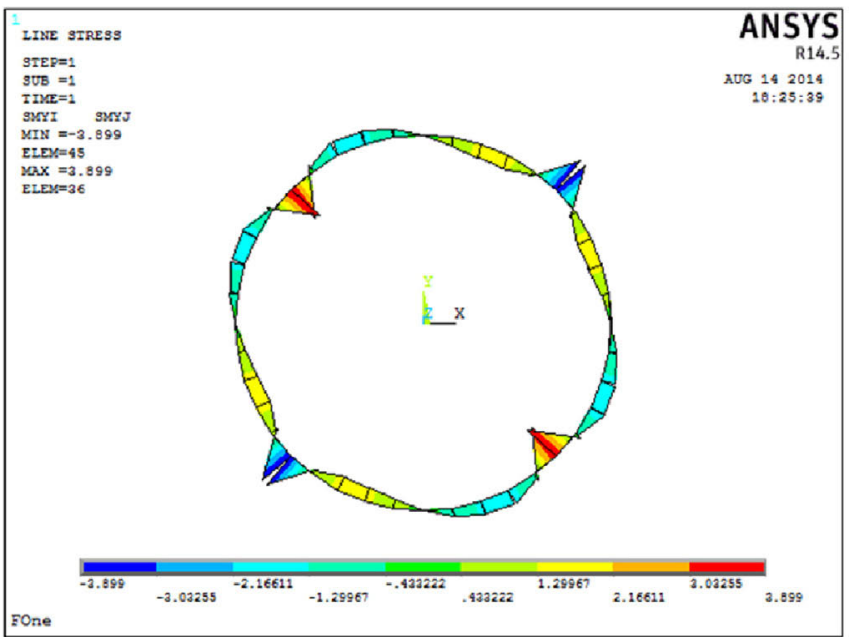

b)

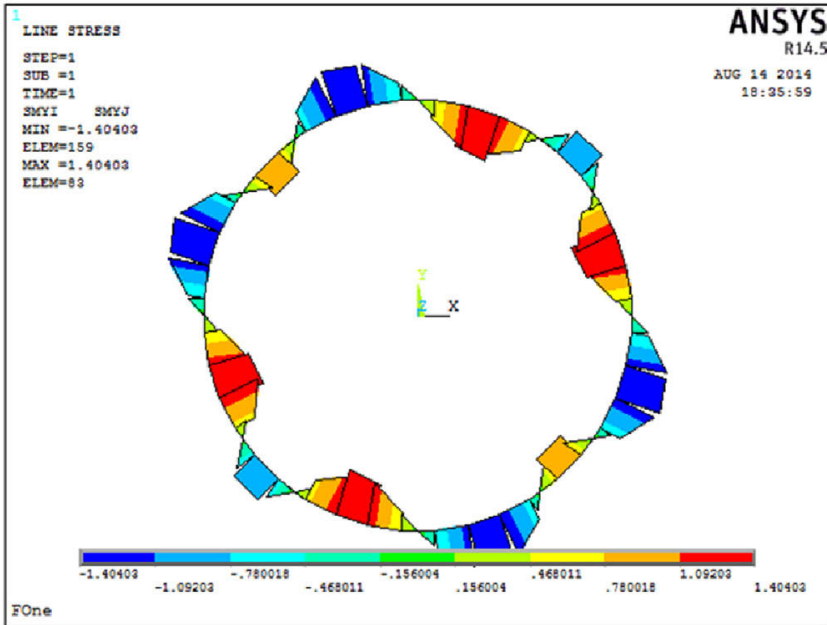

c)

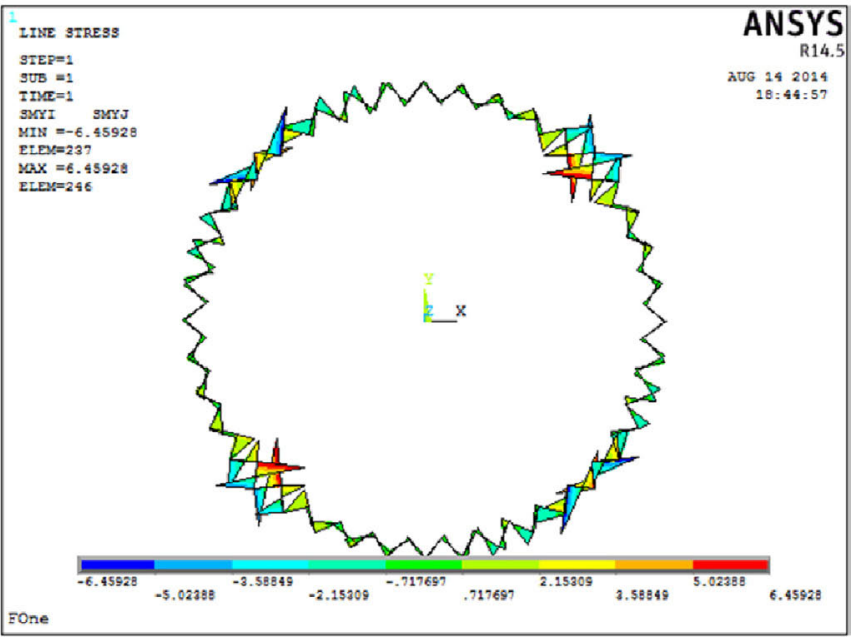

Fig. 5. Stress diagrams $\sigma^{\mathrm{My}}$ for the outer bars (a); for inner bars (b) and stiffeners (c) for the second option of connections 
Table 2. Design stresses

\begin{tabular}{|c|c|c|c|}
\hline \multirow{2}{*}{$\begin{array}{l}\text { Support } \\
\text { Element }\end{array}$} & \multirow{2}{*}{$\begin{array}{c}\text { Stress, } \\
\text { MPa }\end{array}$} & \multicolumn{2}{|c|}{ Options of connections } \\
\hline & & First & Second \\
\hline \multirow{4}{*}{ 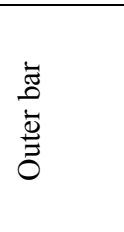 } & $\sigma^{\mathrm{N}}$ & 6,59 & 6,59 \\
\hline & $\sigma^{\mathrm{M}_{\mathrm{z}}}$ & 1,35 & 1,35 \\
\hline & $\sigma^{\mathrm{M}_{\mathrm{y}}}$ & 0 & 0 \\
\hline & $\sigma^{\Sigma}$ & 7,93 & 7,93 \\
\hline \multirow{4}{*}{ 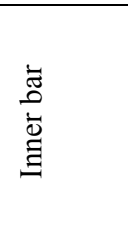 } & $\sigma^{\mathrm{N}}$ & 5,39 & 5,39 \\
\hline & $\sigma^{\mathrm{M}_{\mathrm{z}}}$ & 1,79 & 1,79 \\
\hline & $\sigma^{\mathrm{M}_{\mathrm{y}}}$ & 0 & 0 \\
\hline & $\sigma^{\Sigma}$ & 7,18 & 7,18 \\
\hline \multirow{4}{*}{ 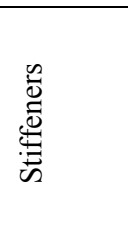 } & $\sigma^{\mathrm{N}}$ & 6,67 & 7,30 \\
\hline & $\sigma^{\mathrm{M}_{\mathrm{z}}}$ & 1,91 & 2,03 \\
\hline & $\sigma^{\mathrm{M}_{\mathrm{y}}}$ & 1,95 & 6,45 \\
\hline & $\sigma^{\Sigma}$ & 9,39 & 14,10 \\
\hline
\end{tabular}

Assuming the design stress under a unit load $\mathrm{q}=1 \mathrm{~N} / \mathrm{mm}=1 \mathrm{kN} / \mathrm{m}$ and characteristic strength of the girder material $\mathrm{Rn}=240 \mathrm{MPa}$, the bearing capacity of a single turn of the lining is defined as follows:

$$
P_{\lim }=\mathrm{q} \frac{\mathrm{R}_{\mathrm{n}}}{\sigma^{\Sigma}} 2 R_{1}=1 \frac{240}{14,1} \cdot 2 \cdot 1,75=60 \mathrm{kN} .
$$

This value correlates well with the bearing capacity of the in-plane annular lining made of SVP17 special section with a clear diameter of $3.00 \mathrm{~m}$ [23] that equals $150 \mathrm{kN}$ under tough operating conditions.

\section{References}

1. Aksenov V.V., Beglyakov V.Y., Kazantsev A.A., Ganovichev S.I., IOP Conf. Ser.: Mater. Sci. Eng., 127, 012030 (2016)

2. Aksenov V.V., Beglyakov V.Y., Kazantsev A.A., Saprykin A.S., IOP Conf. Ser.: Mater. Sci. Eng., 127, 012032 (2016)

3. Aksenov V.V., Beglyakov V.Y., Kazantsev A.A., Doroshenko I.V., IOP Conf. Ser.: Mater. Sci. Eng., 127, 012031 (2016)

4. Chernukhin R.V., Dronov A.A., Blashchuk M.Y., IOP Conf. Ser.: Mater. Sci. Eng., 91, 012086 (2015)

5. Chernukhin R.V., Blaschuk M.Y., Chazov P.A., Blumenstein V.Yu., IOP Conf. Ser.: Mater. Sci. Eng., 142, 012003 (2016)

6. Blaschuk M.Y., Dronov A.A., Ganovichev S.S., IOP Conf. Ser.: Mater. Sci. Eng., 142, 012128 (2016)

7. Aksenov V.V., Walter A.V., Gordeyev A.A., Kosovets A.V., IOP Conf. Ser.: Mater. Sci. Eng., 91, 012088 (2015) 
8. A.A. Khoreshok, S.A. Zhironkin, M.A. Tyulenev, G.A. Barysheva, V.Yu. Blumenstein, M.C. Hellmer, S.V. Potyagailov, IOP Conf. Ser.: Mater. Sci. Eng., 142, 012122 (2016)

9. Revuzhenko A.F., Kazantsev A.A., Glazkov Y.F., Dortman A.A., Applied Mechanics and Materials., 682, 196 (2014)

10. Dimitrios Kolymbas (Springer-Verlag, 2005)

11. Bernhard Maidl, Markus Thewes, Ulrich Maidl, Handbook of tunnel engineering. Volume I: Structures and Methods (Wilhelm Ernst \& Sohn, Verlag für Architektur und technische Wissenschaften GmbH \& Co. KG, 2013)

12. Bernhard Maidl, Markus Thewes, Ulrich Maidl, Handbook of tunnel engineering. Volume II: Basics and Additional Services for Design and Construction (Wilhelm Ernst \& Sohn, Verlag für Architektur und technische Wissenschaften GmbH \& Co. $\mathrm{KG}, 2014)$

13. Austin, S. A., Robins, P. J. and Goodier, C. I. Construction and Repair with Wetprocess Sprayed Concrete and Mortar, The Concrete Society, Technical Report 56 (Draft), Crowthorne, Berkshire (2000)

14. Clayton, C. R. I., Hope, V. S., Heyman, G., van der Berg, J. P. and Bica, A. V. D., Proc. Inst. Civ. Eng. Geotechnical Engineering 143, 119 (2000)

15. Institution of Civil Engineers. Sprayed Concrete Linings (NATM) for Tunnels in Soft Ground. Thomas Telford, London, ICE design and practice guide (1996a)

16. Institution of Civil Engineers. Specification for Piles and Embedded Retaining Walls. Thomas Telford, London (1996b)

17. International Tunnelling Association, Tunnelling and Underground Space Technology 15, 303 (2000)

18. John, M. ASCE III, 27 (1978)

19. Proctor, R. V. and White, T., Rock Tunnelling with Steel Supports (Commercial Shearing and Stamping Co., 1946).

20. Szechy, K. The Art of Tunnelling (1967)

21. Terzaghi, K. Rock defects and loads on tunnel supports in Rock Tunnelling with Steel Supports (eds Proctor, R. V. and White, T.). Commercial Shearing and Stamping Co., Youngstown, USA, 15-19 (1946)

22. Pisarenko G.S., Yakovlev A.P., Matveev V.V. Handbook on Strength of Material (Kiev, Naukova Dumka, 1988)

23. Litvinsky G.G., Gaiko G.I., Kuldirkaev M.I.. Steel frame supports in mining workings (Kiev, Tekhnika (Equipment), 1999) 